\title{
Natural and technogenic elements in soils and water of the lower Yenisey flood plain and terraces: Regional and local landscape geochemical distribution patterns controlled by natural processes
}

\author{
E. Korobova ${ }^{1}$, N. Ukraintseva ${ }^{2}$, V. Surkov ${ }^{3}$, V. Shkinev ${ }^{1}$, \\ J. Brown ${ }^{4}$ and W. Standring ${ }^{4}$ \\ ${ }^{1}$ Vernadsky Institute of Geochemistry and Analytical Chemistry, Russian Ac. of Sciences, \\ 119991 Moscow, Russia \\ ${ }^{2}$ All-Russia Research Institute for Pipeline Construction, Moscow, Russia \\ ${ }^{3}$ Moscow State University, 119991 Moscow, Russia \\ ${ }^{4}$ Norwegian Radiation Protection Authority, 1332 Østerås, Norway
}

\begin{abstract}
Spatial distributions of Cs-137, Cu, Ni, Zn, Fe, Mn, K, Na, Ca in sediments, soils and water of conjugated landscapes within floodplain and coastal areas of the lower Yenisey were determined in a South-North direction from set. Ust'-Port to Cape Shaitansky. The study showed that these elements could be used to reveal the impact of natural and technogenic sources on local landscapes. The marine influence was traced by increasing salinity $\mathrm{Cl}^{-}$content and a decrease in $(\mathrm{Ca}+\mathrm{Mg}) /(\mathrm{Na}+\mathrm{K})$ ratios in ground water in a seaward direction. Accumulative landscapes of the island in the frontal zone of the delta area appeared to be most enriched in terrestrial elements and ions (Ca, $\mathrm{Mg}$, carbonates) and $\mathrm{Cs}-137$. Data suggest that this area acts as the estuary's first filter zone for river load transport. Permafrost leads to relatively enhanced concentrations of $\mathrm{Cu}, \mathrm{Zn}$ and $\mathrm{Cs}-137$ in soil profiles at the bottom of the active layer and to enhanced mobility and accumulation of Fe and $\mathrm{Mn}$ in oxidized zones. The applied methodology seems to be helpful for the rapid geo-ecological survey of large areas subject to graduated impact.
\end{abstract}

\section{INTRODUCTION}

The Lower Yenisey reaches are characterized by marine and continental geochemical interactions under high latitude conditions. Typical "marine" elements enrich the soil and vegetation cover of the adjacent continental areas, not only by air transport but due to the melting of ancient frozen marine deposits [1]. Regional and local redistribution of chemical elements entering the landscape environment occurs within a shallow active layer during short thaw periods and is controlled by periodic freezing processes $[2,3]$. Radionuclides of technogenic origin reach the study area via global aerial fallout and subsequent river transport; additional regional contamination occurred due to direct releases to the river from the Krasnoyarsk Mining and Chemical Combine (KMCC) [4-13]. Industrial complexes at Noril'sk can also contribute to aerial heavy metal contamination of the lower Yenisey River [14]. The dispersed ultra small quantities of these contaminants are disabled to form solid phases and are involved in natural processes of mass migration in water-soluble and/or particulate form together with the hosting aerosols, colloidal and suspended particles or their aggregates formed by typomorphic elements and compounds.

The objectives of this study were: 1 ) to evaluate modern radionuclide and heavy metal contamination levels of the terrestrial landscapes of the Lower Yenisey; 2) to study distribution of natural technogenic elements in soils and sediments of natural landscapes at different distances from the sources; 3 ) to reveal patterns of contamination redistribution due to the landscape geochemical structure of the study sites; 4) to test the efficiency of landscape-geochemical cross-section methodology for the purpose of geo-ecological evaluation over vast areas in the process of monitoring and ecological assessment.

Article published by EDP Sciences and available at http://www.radioprotection.org or http://dx.doi.org/10.1051/radiopro/20095132 


\section{METHODS}

The applied landscape-geochemical strategy involved studying sites located at different distances from the seashore and within different river sedimentation zones (from set. Ust'-Port in the upper delta area, to Cape Shaitansky in the Yenisey Gulf) using floodplain - terrace cross-sections to compare fluvial and modern watershed contamination. On-site fieldwork included: 1) reconnaissance and selection of those sites most suitable for completing a landscape cross-section; 2) leveling; 3) detailed description of geomorphological features, including the soil and vegetation cover along the cross-section, active layer boring to describe lithology and to evaluate the landscape structure and flooding scenarios; 4) determination of the permafrost depth significant with regards to water migration in these tundra landscapes.

Soil profiles were sampled at specific plots that exhibited different conditions of river deposition and atmospheric pollution. Samples were taken continuously with an increment ranging from 2 to $10 \mathrm{~cm}$ to the depth where groundwater or permafrost was present or otherwise to a depth of $50-70 \mathrm{~cm}$. The chemical composition of water samples was determined using potentiometry $\left(\mathrm{NO}_{3}^{-}, \mathrm{Cl}, \mathrm{PO}_{4}^{3-}\right)$, ion selective electrodes $\left(\mathrm{NO}_{3}^{-}, \mathrm{Cl}^{-}\right)$, titrimetry $\left(\mathrm{HCO}_{3}^{-}\right)$, nephelometry $\left(\mathrm{SO}_{4}^{2-}\right)$, photometry $\left(\mathrm{NH}_{4}^{+}, \mathrm{PO}_{4}^{3-}\right)$ techniques and AES-ICP (cations). The main ions in filtered soil water extraction were determined by standard chemical methods of soil analysis [15] and in water samples after ultra-filtration -by ICP-MS. The accuracy of determination did not exceed 5\%. Air dried and homogenized soil and sediment samples were analyzed for major chemical elements using XRF spectrometers ORTEC-TEFA and SPARK-1. Granulometric fractions in selected frozen samples were determined according to [16]. Mineral composition was defined by XRD analyses. Gamma-emitting radionuclides were measured by gammaspectrometry using a HPGe detector (Canberra spectrometer). Detection error varied from 2 to $25 \%$ (the maximum in the range for lower activity concentrations).

\section{RESULTS}

\subsection{Natural marine and terrestrial elements in water soils and soil water extractions}

Salinity and ion composition of ground water and soil water extractions showed a definite decrease in $(\mathrm{Ca}+\mathrm{Mg}) /(\mathrm{Na}+\mathrm{K})$ ratio and an increase of $\mathrm{Cl}^{-}$content in a seaward direction (Figure 1). Soils in the frontal zone of the delta appeared to be most enriched in terrestrial elements and ions $(\mathrm{Ca}, \mathrm{Mg}$, carbonates).

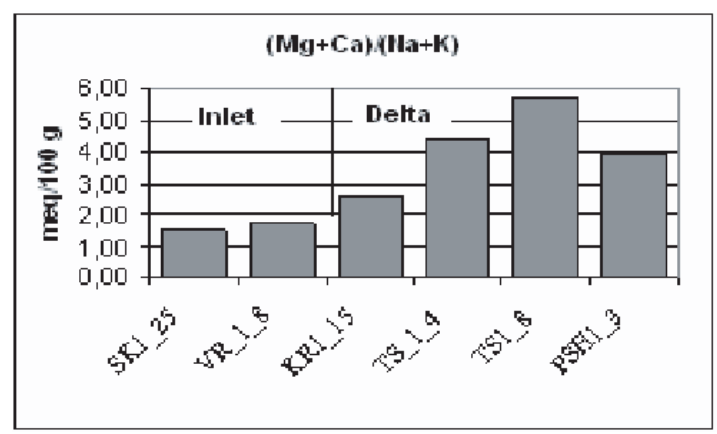

a)

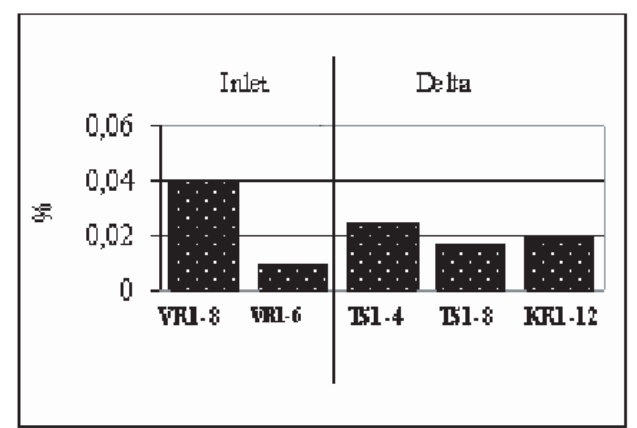

b)

Figure 1. Increase of mean cation ratio (a) and $\mathrm{Cl}^{-}$content at the depth $30 \mathrm{~cm}$ (b) in flood plain soils seaward (from Yenisey inlet to its delta). 
This distribution established the general gradient structure for soluble elements associated with marine water in these continental landscapes and provided insight into the role of the river flood plain and its upper delta section, in sedimentation of terrestrial elements on route to the marine environment.

\subsection{Heavy metals in soils and water}

Consideration of data pertaining to concentrations of elements in soils (Table 1) and water suggests that the Norilsk industrial complex has only produced minor impacts on the area. Compared to the mean content of trace elements in the lithosphere and clays, the analyzed soil samples were enriched in $\mathrm{Cu}$, $\mathrm{Pb}$, and partially in $\mathrm{Cr}$ and $\mathrm{Co}$. Enhanced $\mathrm{Cu}, \mathrm{Cr}$ and $\mathrm{V}$ concentrations and the concentration ratios $\mathrm{Ni}>\mathrm{Co}$ and $\mathrm{V}>\mathrm{Cr}$ are typical for igneous basaltic rock areas and therefore reflect peculiarities of the regional geochemical background.

Table 1. Statistical parameters of chemical element concentration in flood plain soil horizons.

\begin{tabular}{|l|c|c|c|c|c|c|c|}
\hline Element & $\mathrm{n}$ & $\mathrm{X} \min$ & $\mathrm{X} \max$ & Median & Mean & STD & $\mathrm{V}, \%$ \\
\hline $\mathrm{Cu}$ & 66 & 0,0011 & 0,0182 & 0,0066 & 0,0069 & 0,0033 & 48,3 \\
\hline $\mathrm{Zn}$ & 73 & 0,0002 & 0,0150 & 0,0048 & 0,0053 & 0,0030 & 56,3 \\
\hline $\mathrm{Ni}$ & 78 & 0,0002 & 0,0095 & 0,0037 & 0,0040 & 0,0020 & 50,6 \\
\hline $\mathrm{Co}$ & 73 & 0,0003 & 0,0080 & 0,0021 & 0,0021 & 0,0013 & 58,8 \\
\hline $\mathrm{Cr}$ & 79 & 0,0016 & 0,0185 & 0,0101 & 0,0098 & 0,0036 & 37,0 \\
\hline $\mathrm{V}$ & 79 & 0,0041 & 0,0166 & 0,0129 & 0,0123 & 0,0027 & 21,8 \\
\hline $\mathrm{Pb}$ & 57 & 0,0003 & 0,0400 & 0,0025 & 0,0044 & 0,0057 & 129,2 \\
\hline $\mathrm{Fe}$ & 79 & 0,80 & 22,20 & 4,82 & 4,86 & 2,51 & 51,6 \\
\hline $\mathrm{Mn}$ & 79 & 0,0057 & 0,7200 & 0,0890 & 0,0984 & 0,0825 & 83,9 \\
\hline
\end{tabular}

Nevertheless the southward increase of $\mathrm{Ni}$, Co and $\mathrm{Zn}$ content in ground water (Figure 2(a)) and the portion of $\mathrm{Ni}$ present in the coarse fraction (Figure 2(b)) together with the enhanced Ti-normalized top layer enrichment factor ( $\mathrm{Cea}$ ) for $\mathrm{Pb}, \mathrm{Cu}$ and $\mathrm{Zn}$ in soils at watershed locations and in mosses and lichens may reflect the influence of Norilsk [17].

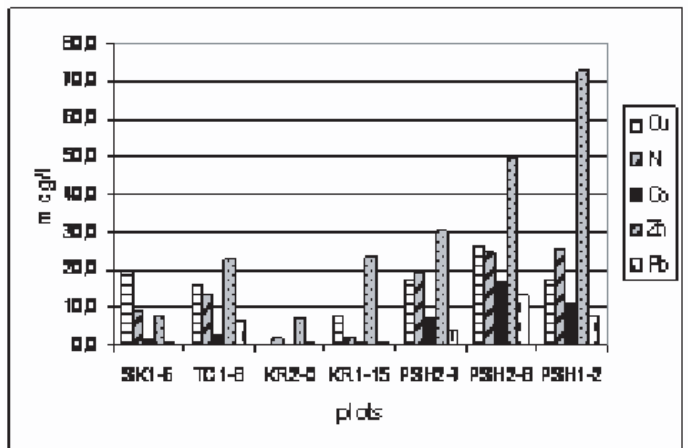

a)

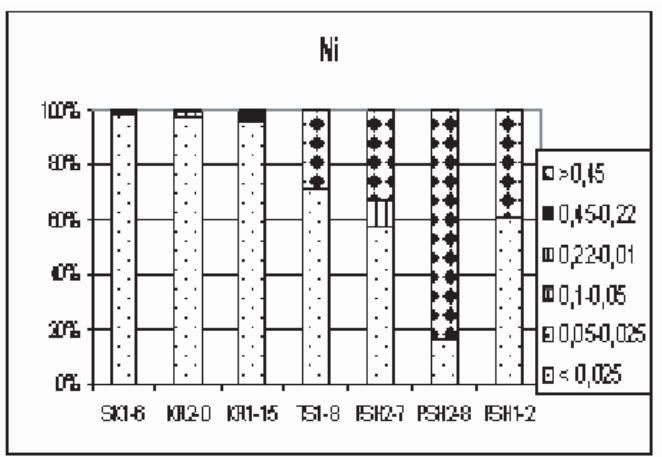

b)

Figure 2. Heavy metal content (a) and Ni in different fractions (b, fraction size in $\mathrm{mm}$ ) in ground water at different distances from Norilsk. SK - Cape Shaitansky (gulf); TC - Tysyara Island (middle delta); KR - near set. Karaul, high terrace; PSH - Pashkov Island (upper delta; different flood plain levels: plot 1-2 - low level, the head of the isle; plot 2-7 - medium level delta, central part of the isle; 2-8 - the slope of the high level core).

Natural trace element distributions in soil layers conform to the theory of geochemical barriers and migration with typomorphic carriers. Biogeochemical barriers are typical for $\mathrm{Cu}$ and $\mathrm{Zn}$ (in organic layers $\mathrm{r}_{0.05}=0.627, \mathrm{n}=11$ ). In the gley loamy and clay horizons a significant correlation was found 
for $\mathrm{Ni}$ and $\mathrm{V}$ with $\mathrm{Fe}\left(\mathrm{r}_{0.05}=0.861,0.674, \mathrm{n}=11\right)$ and $\mathrm{Mn}\left(\mathrm{r}_{0.05}=0.823,0.785, \mathrm{n}=11\right)$. Cobalt exhibited a rare increase in concentration at the sorption barrier and in general correlated with total $\mathrm{Fe}$ concentrations, predominantly in non-organic horizons. The presence of permafrost leads to relatively elevated concentrations of $\mathrm{Cu}$ and $\mathrm{Zn}$ in soil profiles at the bottom of the active layer and to enhanced mobility and accumulation of Fe and Mn in oxidized zones [17].

\subsection{Cs-137 in sediments and soils}

${ }^{137} \mathrm{Cs}$ exhibited various patterns of distribution in watershed and flood plain conditions and in different estuary zones. Total contamination densities of the sampled soil cores varied considerably from 0.9 to $88 \mathrm{kBq} / \mathrm{m}^{2}$. Highest values were observed on flood plains, especially the island plots and the low flood plain of the upper delta at the head of Pashkov Island. In undisturbed tundra soils of the terrace landscapes, maximum ${ }^{137} \mathrm{Cs}$ levels were determined in top layers with a characteristic slight increase over the permafrost table, presumably reflecting a protracted cryogenic concentration in the liquid phase. On terrace slopes with land slides, sub-surface peaks in ${ }^{137} \mathrm{Cs}$ levels indicated buried top soils (Figure 3).

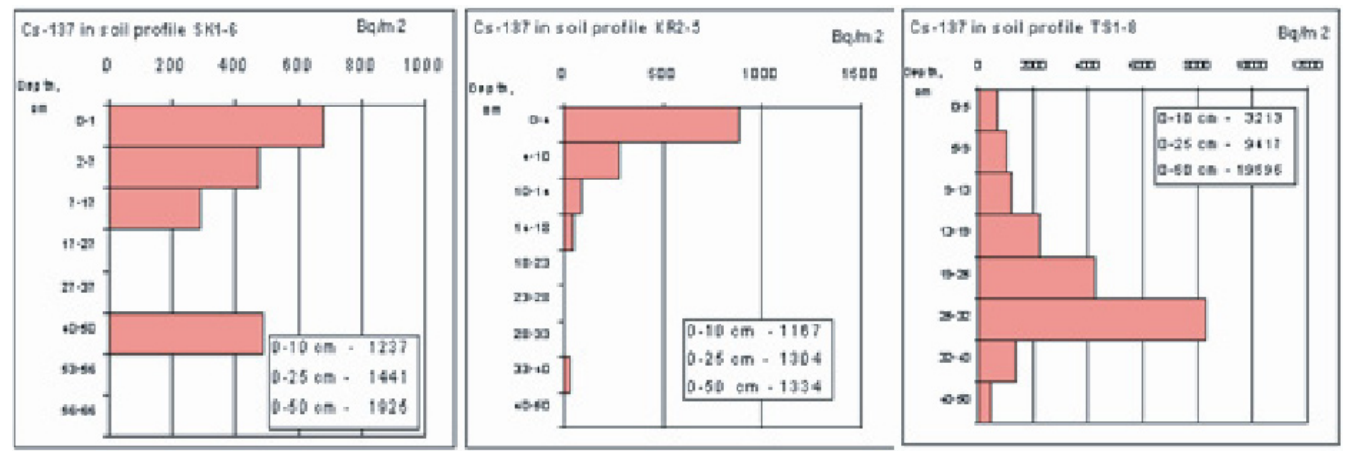

Figure 3. Cs-137 depth profiles in high terrace soils (SK - Cape Shaitansky, the slope with buried topsoil, KR near set. Karaul, polygonal tundra) and flood plain soils (TS - Tysyara Island, medium level gentle slope, buried horizon with maximum Cs-137 accumulation).

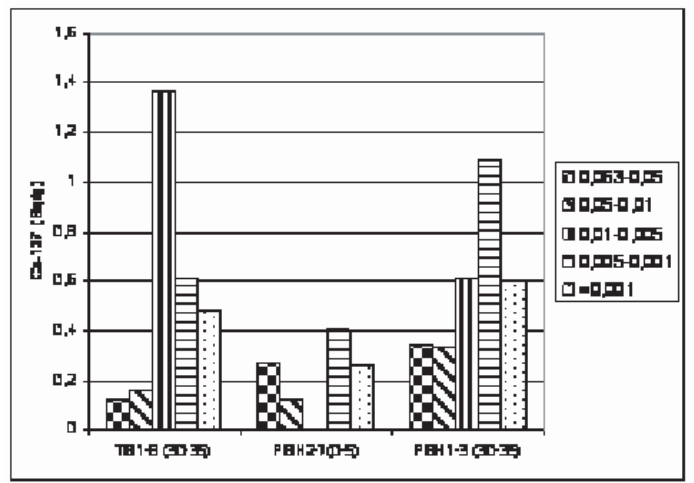

a)

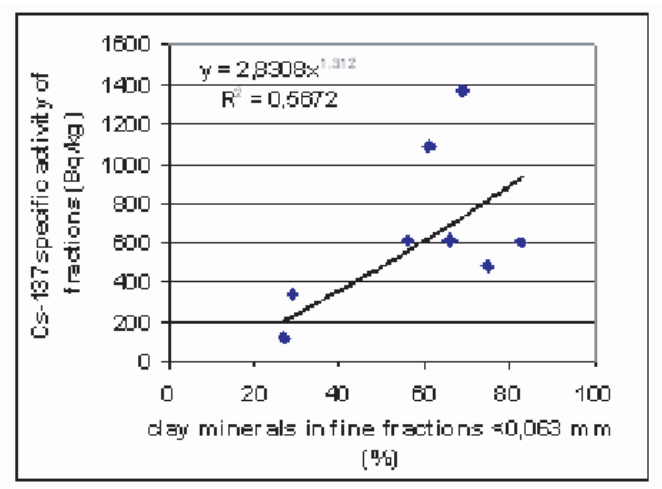

b)

Figure 4. Cs-137 specific activity in the fines from the most contaminated soil horizons. TS - Tysyara Island, medium level flood plain, PSH - Pashkov Island, 2-7 - medium level flood plain, central part of the island, 1-3 - low level flood plain, the ridge at the head of the island. The depth of the soil horizon is indicated in parenthesis. Legend shows the size of the fine fractions in $\mathrm{mm}$. 
Soil layers of six island soil profiles were noted for the predominance of fines $(<0.063 \mathrm{~mm})$ with median values for each silt or clay fraction ranging within 10-18\%. Maximum Cs-137 specific activities were associated with the medium and fine silt particles (Figure 4). The presence of ${ }^{60} \mathrm{Co}$ in the PSH1-3 soil profile provides evidence to suggest that contaminants from KMCC radioactive releases have reached the Pashkov Island and the relatively enhanced ${ }^{137} \mathrm{Cs}$ contamination could be formed by burial of sediment labeled by discharges from this source. The coincidence of radiocesium sub-surface peaks in some horizons with a number of trace elements $(\mathrm{Cu}, \mathrm{Ni}, \mathrm{Cr}$ and $\mathrm{Zn})$ may indicate the possibility of heavy metal contamination with long-distance transported suspended load.

The lower horizon of the Tysyara Isle profile could also contain regional contamination since contamination of the silt fraction is comparable to that observed at Pashkov Island (Figure 4(a)). ${ }^{137} \mathrm{Cs}$ activity concentrations in different granulometric fractions of the selected most contaminated flood plain soil layers was related to the portion of clay minerals (Fig. 4(b)). For the contaminated horizons sampled at Tysyara Island, ${ }^{137} \mathrm{Cs}$ activity concentration were associated with illite (hydromica) minerals in different fine fractions, whereas the contamination was associated with smectite within fines at the Pashkov Study site.

\section{CONCLUSION}

A geochemical study of soils, sediments and water of the Lower Yenisey natural terrace and flood plain landscapes in a South-North direction enabled gradients of marine and terrestrial impact and local permafrost effects, indicated by particular macro- and microelements, to be revealed. The study showed that chemical elements of anthropogenic origin followed the natural pathways. Island flood plain sites, in the upper Yenisey where the delta widens, appear to be acting as the estuary's first geochemical sedimentation barrier to the river transport of both natural terrestrial and technogenic $\left({ }^{137} \mathrm{Cs}\right)$ elements.

Site-specific sampling in geochemically contrasting conditions with due regard to landscape geochemical structure and river deposition made it possible to detect technogenic contamination and to establish patterns of lateral and vertical variation with respect to location in natural landscapes reflecting the natural processes of sorption and accumulation. The results can be helpful in selecting sites in the process of conducting geo-ecological assessments and long-term monitoring.

\section{Acknowledgments}

Investigations were performed for the EU Project "ESTABLISH" and continued on GEOKHI initiative in the Ust'Port area in cooperation with the Moscow state University. The authors are thankful to Dr. V. Linnik (Vernadsky Institute) for advice and participation in the Yenisey field work and to Dr. O. Stepanets and the crew of the Vernadsky Institute RV for assistance in terrestrial studies of 2002, to Dr. V. Grebenets (Moscow State University), T. Alekseeva (Institute of Oceanology, Rus. Ac. of Sciences), V. Krupskaya (IGEM, Rus. Ac. of Sci.), S. Kirov (Institute of Global Ecology and Climate, Rus. Ac. of Sci.), S. Sorokin (Soil Science Institute), E. Sizov, E. Sedykh, N. Starshinova (Vernadsky Institute) for assistance in field work and laboratory analysis of the samples.

\section{References}

[1] G.I. Dubikov. Composition and cryogenic structure of permafrost in West Siberia. (GEOS, Moscow, 2002).

[2] N.P. Anisimova. Cryohydrogeochemical peculiarities of the frozen zone (Nauka, Novosibirsk, 1981).

[3] E.S. Mil'kov and S.E. Grechishchev. Permafrost and developing the oil and gas regions. (GEOS, Moscow, 2002).

[4] A.V. Nossov, M.V. Ashanin, A.B. Ivanov and A.M. Martynova, Atomnaya Energiya 74, 2 (1993) pp. $144-150$. 
[5] S.M. Vakulovsky, I.I. Kryshev, A.I. Nikitin, et al., J. Environ., Radioactivity 29, 3 (1995) pp. $225-236$.

[6] S.M.B. Wright, J. Howard, P. Strand et al. Environmental pollution 4, (1997) pp. 131-143.

[7] P. Strand, M. Balonov, A. Aarkrog, et al.. AMAP Assessment Report: Arctic Pollution Issues. Radioactivity. (NRPA, Oslo, 1998).

[8] A. Evenset, S. Dahle, D. Loring, et al. KAREX-94. An environmental survey of the Kara Sea and the estuaries of $\mathrm{Ob}$ and Yenisei (Polar Environmental Center, Tromso, 1999).

[9] Yu.V. Kuznetsov, V.K. Legin,; V.N. Strukov, A.P. Novikov, T.A. Goryachenkova, A.Ye. Shishlov, and Yu.V. Savitsky, Radiokhimia 42, 5 (2000) pp. 470-477.

[10] E.V. Kvasnikova, V.M. Kertsman; I.M. Nazarov, et al. in Proceedings of the Inrernational Conference on Radioactivity following nuclear explosions and accidents, 1, St.-Petersburg, 2000, edited by Yu.A. Izrael (Hydrometeoizdat, St.-Petersburg, 2000). pp. 549-554.

[11] J. Brown, S. Wright, V. Linnik et al. Source development and transport of radioactive contamination through the use of sattelite imagery. Final Report for project ERB IC-15-CT-980219 "STREAM" (NRPA, Østerås; 2002).

[12] Contaminants in sediment deposits of the Yenisey Estuary. Report Deliverable 5 to the European Union Within the EC-Copernicus Project ICA-CT-2000-10008 "ESTABLISH", edited by W. Standring (NRPA, Østerås, 2003).

[13] F.V. Sukhorukov, A.G. Degermendzhi, V.M. Belolipetsky et al. Patterns of radionuclide distribution and migration in the valley of the Yenisey river. (SO RAN, GEO, Novosibirsk, 2004).

[14] V.I. Solomatin, A.V. Evseev, A.V. Korzun and A.V. Kuznetsova. Geochemistry of the atmospheric precipitation, the surface waters and underground ice in Arctic landscapes, (VINITI, Moscow, 1989).

[15] E.V. Arinushkina. Manual for the soil chemical analysis (Moscow State University, Moscow, 1961).

[16] V.N. Svalnov and T.N. Alekseeva. Granulometric composition of the World Ocean sediments. (Nauka, Moscow, 2005).

[17] E.M. Korobova, N.G. Ukraintseva, V.V. Surkov, V.M. Shkinev and E.M. Sedykh. Elementsindicators of techogenic impact in terrestrial landscapes of the River Yenisey Delta, in Proceedings of the International Conference on Geochemistry of biosphere (devoted to 90-th anniversary of A.I.Perelman), Moscow, 2006, edited by N.S. Kasimov, N.S. Bortnikov, V.I. Velichkin, A.N. Gennadiev and V.A. Snytko (Oikumena, Smolensk, 2006), pp. 160-162. 